\title{
Necessity and feasibility of improving the residual resistance factor of polymer flooding in heavy oil reservoirs
}

\author{
Shi Leiting*, Ye Zhongbin, Zhang Zhuo, Zhou Changjiang, Zhu Shanshan \\ and Guo Zhidong
}

State Key Laboratory of Oil and Gas Reservoir Geology and Exploitation, Southwest Petroleum University, Chengdu, Sichuan 610500, China

(c) China University of Petroleum (Beijing) and Springer-Verlag Berlin Heidelberg 2010

\begin{abstract}
The efficiency of water flooding in heavy oil reservoirs would be improved by increasing the viscosity of the displacing phase, but the sweep efficiency is not of significance due to the low mobility of the vicious oil. On the basis of mobility control theory, increasing the residual resistance factor not only reduces the water-oil mobility ratio but also decreases the requirement for viscosity enhancement of the polymer solution. The residual resistance factor caused by hydrophobic associating polymer solution is higher than that caused by polyacrylamide solution in brine containing high concentrations of calcium and magnesium ions. The results of numerical simulations show that the polymer flooding efficiency improved by increasing the residual resistance factor is far better than that by only increasing solution viscosity. The recovery factor of heavy oil reservoirs $(70 \mathrm{mPa} \cdot \mathrm{s})$ can be enhanced by hydrophobic associating polymer solution of high residual resistance factor (more than 3 ) and high effective viscosity (24 $\mathrm{mPa} \cdot \mathrm{s})$. Therefore, increasing the residual resistance factor of the polymer solution not only decreases the requirement for the viscosity of polymer solution injected into heavy oil reservoirs but also is favorable to enhanced oil recovery during polymer flooding.
\end{abstract}

Key words: Heavy oil reservoir, polymer flooding, mobility control, residual resistance factor, viscosity

\section{Introduction}

Heavy oil reservoirs form one of the most important resources in China. Heavy oil is characterized by high viscosity and low-degree APT gravity. In some Chinese heavy oil reservoirs the oil viscosity is $50-100 \mathrm{mPa} \cdot \mathrm{s}$ and the heavy oil is mainly displaced by water. Application of water injection for heavy oil recovery suffers from high mobility of water, leading to unstable displacement. In addition, reservoir heterogeneity exacerbates the unstable displacement. Once water breakthrough occurs, the water cut increases significantly. Therefore, the oil recovery in these reservoirs is low due to high water mobility and low oil mobility (i.e. unfavorable water-oil mobility ratio). Nevertheless, heavy oil trapped in these reservoirs in China is mainly recovered by water flooding (Jiang and Xu, 1999; Xu et al, 2007; Zhou, 2007; Aktas et al, 2008).

Addition of polymer to injection water not only reduces water-phase mobility, but also provides a solution to the problem of unstable displacement. Polymer flooding in

*Corresponding author. email: slting@swpu.edu.cn Received May 6, 2009 heavy oil reservoirs showed that oil recovery increased by 5\%-8\% (Zhou et al, 2004; Zhang et al, 2007), lower than an incremental oil recovery of $10 \%$ of polymer flooding in conventional reservoirs (Wang et al, 2005). More effective mobility control provided by polymer flood in the heavy oil reservoirs is required than that in conventional oil reservoir due to unfavorable water-oil mobility ratio. Although the oil recovery efficiency of polymer flooding would be improved by increasing the active viscosity of polymer solution, the solution viscosity does not increase as much because of the limitation of injection ability, economic benefits, etc (Chen et al, 1992; Shen et al, 2004; Li et al, 2006; Du et al, 2008; Guo et al, 2008). Therefore, increasing the mobility control with polymer flooding is a key factor for successful polymer flooding in heavy oil reservoirs.

\section{Methods for improving mobility control with polymer flooding}

The water-oil mobility ratio has a direct influence on the waterflooding sweep efficiency (Ye, 2007), thereby affecting oil recovery. The water flooding mobility ratio was calculated by the following equation: 


$$
M_{\mathrm{wo}}=\frac{K_{\mathrm{w}} / u_{\mathrm{w}}}{K_{\mathrm{o}} / u_{\mathrm{o}}}
$$

where $K_{\mathrm{w}}$ is the water phase permeability, $10^{-3} \mu \mathrm{m}^{2} ; K_{\mathrm{o}}$ is the oil phase permeability, $10^{-3} \mu^{2} ; \mu_{\mathrm{w}}$ is the water viscosity, $\mathrm{mPa} \cdot \mathrm{s}$; and $\mu_{\mathrm{o}}$ is the oil viscosity, $\mathrm{mPa} \cdot \mathrm{s}$.

Most polymer flooding operations were conducted after water breakthrough. The oil displaced by the flood front of polymer solution is residual oil trapped at high water saturations. Thus, the mobility ratio of polymer solution to oil, $M_{\mathrm{po}}$ is defined as follows:

$$
M_{\mathrm{po}}=\frac{\lambda_{\mathrm{p}}}{\lambda_{\mathrm{o}}}
$$

where $M_{\mathrm{po}}$ is the mobility ratio of polymer solution to oil; $\lambda_{\mathrm{p}}$ is the mobility of the polymer solution, $\mu \mathrm{m}^{2} /(\mathrm{mPa} \cdot \mathrm{s})$; and $\lambda_{\mathrm{o}}$ is the oil mobility, $\mu \mathrm{m}^{2} /(\mathrm{mPa} \cdot \mathrm{s})$.

The resistance factor is a measurement of the decrease in mobility of a polymer solution in comparison with injection water and can be calculated as follows:

$$
F_{\mathrm{R}}=\frac{\lambda_{\mathrm{w}}}{\lambda_{\mathrm{p}}}=\frac{K_{\mathrm{w}} / u_{\mathrm{w}}}{K_{\mathrm{p}} / u_{\mathrm{p}}}
$$

where $F_{\mathrm{R}}$ is the resistance factor; $K_{\mathrm{p}}$ is the permeability to the polymer solution, $10^{-3} \mu \mathrm{m}^{2}$; and $\mu_{\mathrm{p}}$ is the viscosity of the polymer solution.

The combination of Eq. (2) and Eq. (3) gives the relationship between polymer solution-oil mobility ratio and water-oil mobility ratio:

$$
M_{\mathrm{po}}=\frac{M_{\mathrm{wo}}}{F_{\mathrm{R}}}
$$

Thus, for a special oil layer, trying to keep $M_{\mathrm{po}}$ of polymer solution equal to or lower than 1 will result in better sweep efficiency. And the resistance factor is expressed as:

$$
F_{\mathrm{R}}=\frac{M_{\text {wo }}}{M_{\text {po }}} \geq M_{\text {wo }}
$$

The resistance factor of the polymer solution is a measure of mobility control with polymer flood. The resistance factor and residual resistance factor, obtained at the same injection rates, would meet the following relationship (Wu et al, 2006):

$$
F_{\mathrm{R}}=F_{\mathrm{RR}} \frac{\mu_{\mathrm{p}}}{\mu_{\mathrm{w}}}
$$

The residual resistance factor is the ratio of the permeability to brine to that after the injection of a polymer solution, which is a measurement of the permeability reduction caused by polymer solution. In order to achieve favorable mobility control $(M=1)$, the requirement for polymer solution can be derived from combining Eq. (3) through Eq. (6):

$$
\mu_{\mathrm{p}}=\frac{\mu_{\mathrm{o}}}{F_{\mathrm{RR}}}
$$

In general, the residual resistance factor caused by partially hydrolyzed polyacrylamide solution is 1.0 3.0, indicating a limited capacity to reduce water-phase permeability. Therefore, we can increase the viscosity of the polymer solution to improve the mobility control. Eqs. (5) through (7) indicate that polymers should have the ability to increase the viscosity of displacement fluids for heavy oil reservoirs. The larger the ratio of in-situ viscosity of polymer solution to oil viscosity, the higher the oil recovery enhanced by polymer flooding (Song, 2003).

There are two basic methods of increasing the viscosity of polymer solutions. The first one is to increase the polymer solution concentration. The second is to increase the molecular weight of polymer (Jiang, 1993). The former will increase the polymer dosage and increase the costs as well. However, for the latter the in-situ effective viscosity of displacement fluid reduces significantly due to the shearing effect of polymer injection pumps, pipelines, perforation holes and reservoir porous media, etc. This will reduce the polymer flooding efficiency (Liu, 2006). When the viscosity of heavy oil is $70 \mathrm{mPa} \cdot \mathrm{s}$, it requires that the in-situ viscosity of polymer solution should be $210 \mathrm{mPa} \cdot \mathrm{s}$ in light of favorable mobility ratio (Xu et al, 2007). Under present economic and technical conditions, one of the difficulties is to obtain a polymer such high in-situ viscosity. According to Eq. (5) through Eq. (7), if the residual resistance factor of polymer solution is 6 , the in-situ viscosity of polymer solution needed is $52.5 \mathrm{mPa} \cdot \mathrm{s}$. Therefore, it will decrease the requirement for the viscosity of polymer solution by raising the residual resistance factor and ultimately improve the polymer flooding efficiency in heavy oil reservoirs.

\section{The effect of properties of different polymer solutions on mobility control}

The properties of polymer solutions, such as viscosity, temperature resistance, salt tolerance, and shearing strength, can be improved by increasing the polymer chain length or changing the functional groups at both ends of a polymer chain. In this paper, the properties of two polymer solutions are measured under conditions of S heavy oil reservoir in B Oil Field.

\subsection{Viscosity enhancement of polymer solutions}

The brine used in the experiments had similar composition to the water injected into S heavy oil reservoir in B Oil Field. Table 1 presents the brine composition. Before use, the brine was filtered through a $0.45-\mu \mathrm{m}$ Millipore filter to remove solids.

Table 1 The composition of brine used

\begin{tabular}{ccccccccc}
\hline Component & $\mathrm{Na}^{+}$ & $\mathrm{Ca}^{2+}$ & $\mathrm{Mg}^{2+}$ & $\mathrm{CO}_{3}{ }^{2-}$ & $\mathrm{HCO}_{3}{ }^{-}$ & $\mathrm{SO}_{4}{ }^{2-}$ & $\mathrm{Cl}^{-}$ & $\begin{array}{c}\text { Total dissolved } \\
\text { solids }\end{array}$ \\
\hline $\begin{array}{c}\text { Concentration } \\
\mathrm{mg} / \mathrm{L}\end{array}$ & 3091 & 276 & 158 & 14 & 311 & 85 & 5436 & 9374 \\
\hline
\end{tabular}

Two types of polymers, partially hydrolyzed polyacrylamide (HPAM 3830) and hydrophobic associating polymer (HAP 0312), were used in this study.

HPAM 3830, an anionic polymer of ultra-high molecular weight, has a large number of anionic charges on the polymer chain. The molecular chain is stretched in fresh 
water due to electrostatic repulsion among anions and then its hydrodynamic volume increases. Neighboring chains entangle with each other to increase the solution viscosity. Adding salt to the solution shields the anionic charges on the molecules and decreases hydrodynamic volume and solution viscosity. Especially, high concentration of divalent cations has a dramatic effect on the polymer viscosity.

HAP 0312 is an associating polymer, containing hydrophobic groups along the molecular chain. Molecular association will be occur in brine to form network structures, thereby increasing solution viscosity. The molecular weight of HAP 0312 is lower than that of HPAM 3830, but the HAP 0312 is found to be favorable to the enhancement of solution viscosity due to the intermolecular and intramolecular association. Moreover, the addition of salt increases the number and the strength of hydrophobic groups, which results in an increase in solution viscosity. So, HAP 0312 has better ability to increase solution viscosity than HPAM 3830.

The $0.5 \mathrm{wt} \%$ polymer solution was prepared at $45^{\circ} \mathrm{C}$ by dilution with filtered brine to the desired concentration. The viscosity of the resulting polymer solution was measured at $65{ }^{\circ} \mathrm{C}$ and $7.34 \mathrm{~s}^{-1}$ after being filtered through a $25-\mu \mathrm{m}$ filter membrane. Fig. 1 shows the relationship between viscosity and the concentration of polymer in solutions.

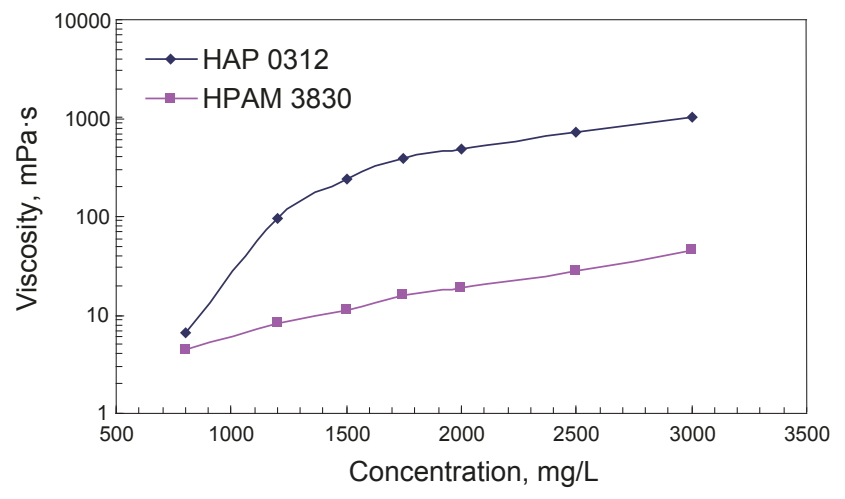

Fig. 1 Viscosity versus polymer concentration $\left(65^{\circ} \mathrm{C}, 7.34 \mathrm{~s}^{-1}\right)$

\subsection{Mobility control with polymer solutions}

Linear sand packs $(50 \mathrm{~cm}$ long, ID $0.8 \mathrm{~cm})$, filled with 40-120 mesh quartz sand, were used to simulate reservoir porous media. According to the reservoir permeability, the permeability of the sand packs was controlled in the range from $1000 \times 10^{-3}$ to $3,000 \times 10^{-3} \mu^{2}$. The schematic diagram of the linear sand-pack tests is shown in Fig. 2.

The residual resistance factor to water, which was caused by polymer solution, was determined as follows:

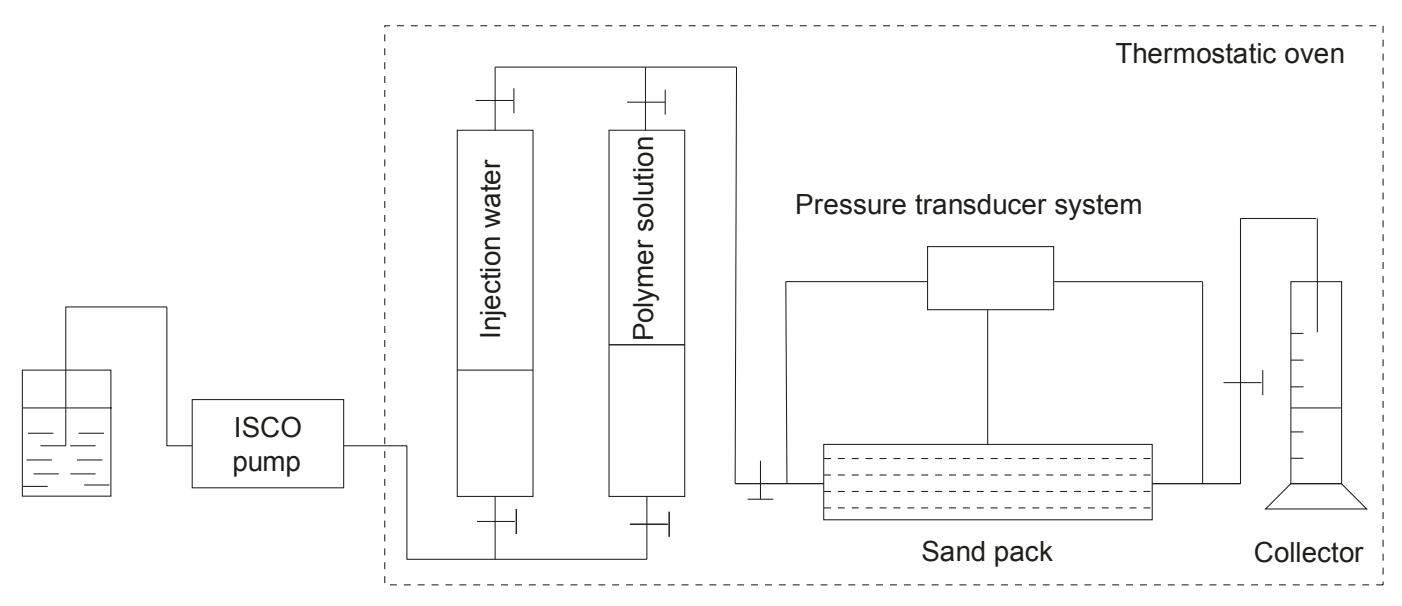

Fig. 2 Laboratory apparatus for linear sand-pack tests

1) The linear sand pack was evacuated and then saturated with brine. Brine was injected at a rate of $0.5 \mathrm{~mL} / \mathrm{min}$ until the pressure was stabilized, and then the permeability and porosity were measured.

2) Polymer solution was injected into the linear sand pack at a rate of $0.5 \mathrm{~mL} / \mathrm{min}$ until the displacement pressures at two pressure-measuring points were stabilized. The stabilized pressures were recorded and the resistance factor was calculated.

3) Brine was injected into the sand pack at a rate of $0.5 \mathrm{~mL} / \mathrm{min}$ until the displacement pressures at the two pressure-measuring points were stabilized. The stabilized pressures were recorded and the residual resistance factor was calculated.

The resistance factor and residual resistance factor caused by HAP 0312 and HPAM 3830 solution are shown in Table 2.
Table 2 Resistance factor and residual resistance factor of polymer solutions

\begin{tabular}{ccccc}
\hline Polymer & $\begin{array}{c}\text { Viscosity } \\
\mathrm{mPa} \cdot \mathrm{s}\end{array}$ & $\begin{array}{c}\text { Permeability } \\
10^{-3} \mu \mathrm{m}^{2}\end{array}$ & $\begin{array}{c}\text { Resistance } \\
\text { factor }\end{array}$ & $\begin{array}{c}\text { Residual resistance } \\
\text { factor }\end{array}$ \\
\hline HAP 0312 & 395.1 & 1983 & 96.1 & 12.4 \\
HPAM 3830 & 15.5 & 1610 & 34.8 & 2.5 \\
\hline
\end{tabular}

Table 2 shows that the resistance effect caused by HAP 0312 solution was higher than that caused by HPAM 3830 solution. Hence, HAP 0312 solution has better ability to control fluid mobility than HPAM 3830 solution, and the literature showed the same result as well (Eoff et al 2003; Han et al, 2006; Levitt and Pope, 2008; Niu et al, 2001; Ren et al, 2006; Vasquez et al, 2009; Ye et al, 2007; Zhou et al, 2007; 2008). 
Intermolecular entanglement of HPAM 3830 chains adsorbed on the sandstone surface will increase resistance to flow in porous media, so as to control fluid mobility. The intermolecular entanglement effect is reduced after water flush. Hence the HPAM 3830 has a low ability to block highpermeability channels and the residual resistance factor is relatively low. Increases in viscosity and shearing strength will be achieved due to intermolecular association of HAP 0312 chains. When the HAP 0312 solution is injected into porous media, the resistance to flow increases because of intermolecular association between molecules in pores and polymer molecules adsorbed on sandstone surface, which reduces the channel permeability. Nevertheless, intermolecular association has no effect on the injectivity of polymer solutions and produces a high resistance effect because of partial intermolecular association after water flush. The resistance factor and residual resistance factor caused by HAP 0312 solution are higher than those caused by HPAM 3830 solution due to the differences of molecular structure and solution properties.

\section{The effect of residual resistance factor on polymer flooding in heavy oil reservoirs}

Eqs. (5)-(7) indicate that the polymer solution with relatively strong capacity of viscosity enhancement and resulting relatively high residual resistance factor would contribute to improving the polymer flooding efficiency of heavy oil reservoirs.

\subsection{Residual resistance factor}

The resistance factor and residual resistance factor created in porous media, whose permeability values are approximately $2,000 \times 10^{-3} \mu^{2}$, by HAP 0312 and HPAM 3830 solutions at different concentrations are shown in Fig. 3.

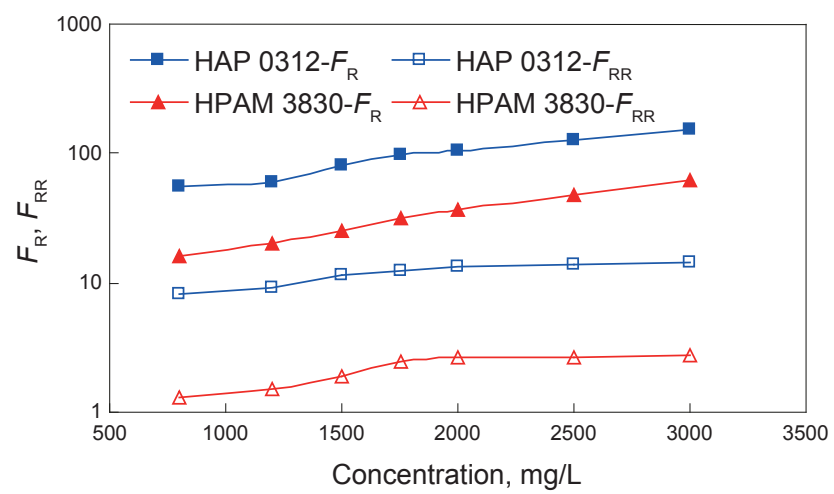

Fig. 3 Resistance effect produced by polymer solutions with different concentrations

The resistance effect produced by polymer solutions in high-permeability porous media increased as the concentration of polymer in injected solution increased but the amplification reduced gradually. In the porous media with approximately equal permeability, the resistance effect produced by HAP 0312 solution was far larger than that produced by HPAM 3830 solution. The residual resistance factor caused by
HAP 0312 solution was more than 3, while the value of the HPAM 3830 solution was less than 3 . These results show that high resistance effect can be achieved by injecting HAP 0312 solution due to intermolecular association of HAP 3830 chains, while the resistance effect produced by HPAM 3830 solution is limited by merely relying on intermolecular entanglement.

Fig. 4 shows the relationship between $F_{\mathrm{RR}} \times \mu_{\mathrm{p}}$ and HAP 0312 concentration in injected solution. It shows that the residual resistance factor and viscosity of HAP 0312 solution are both functions of polymer concentration. According to Eq. (5) through Eq. (7), HAP 0312 solution with certain concentration range can meet the requirement for mobility control with polymer flooding in heavy oil reservoirs. Increasing the polymer concentration would enable the application of polymer flooding in heavy oil reservoirs.

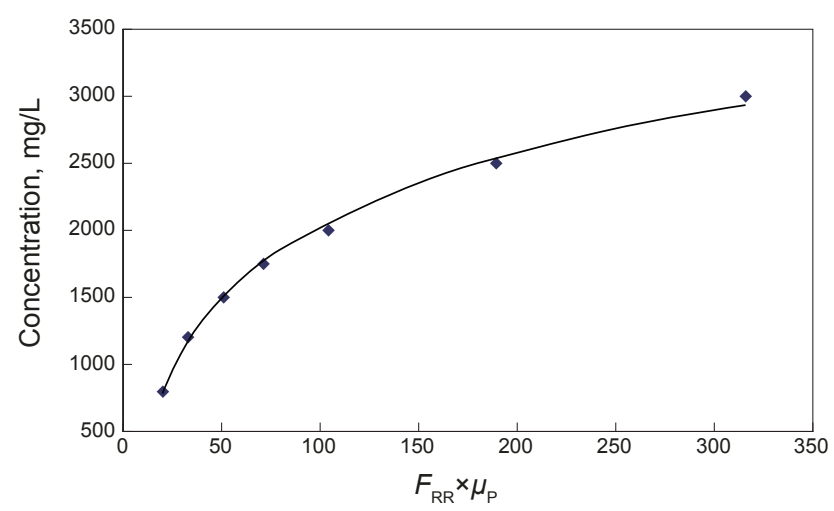

Fig. 4 The relationship between concentration and $F_{\mathrm{RR}} \times \mu_{\mathrm{p}}$ of HAP 0312 solution

\subsection{The effect of residual resistance factor on recovery factor}

The effect of residual resistance factor on polymer displacement was studied using numerical simulation. Combined with the situation of S heavy oil reservoir in B Oil Field, an anisotropic stratified model was built. An inverted five-spot pattern, including 4 injectors and 9 producers, was adopted in this model. Well spacing between the injector and the producer is 350 meters. It is vertically divided into 6 layers and the effective thickness of each layer is 5 meters. The grid system of the numerical simulation is $50 \times 50 \times 6$ and the porosity values of each layer are $25 \%, 27 \%, 29 \%$, $31 \%, 33 \%$ and $34 \%$, respectively, and the average porosity is $29.8 \%$. The permeability values of each layer are $500 \times 10^{-3}$, $800 \times 10^{-3}, 1,000 \times 10^{-3}, 1,500 \times 10^{-3}, 2,500 \times 10^{-3}$, and $3,500 \times 10^{-3}$ $\mu \mathrm{m}^{2}$, respectively, and the average permeability is $1,633 \times 10^{-3}$ $\mu \mathrm{m}^{2}$ and its variation coefficient is 0.644 . The crude oil viscosity is $70 \mathrm{mPa} \cdot \mathrm{s}$ at $65{ }^{\circ} \mathrm{C}$. Water flooding continues until the water cut reaches $95 \%$. In addition, other parameters primarily remain the same with real geological parameters of $\mathrm{S}$ heavy oil reservoir in B Oil Field.

The effect of residual resistance factor and effective insitu viscosity on incremental recovery was studied and the results are shown in Fig. 5.

Fig. 5 shows that when the residual resistance factor 
is constant, the incremental recovery slows down as the viscosity of polymer solution increases. It is also obvious that the incremental recovery increases remarkably as the residual resistance factor, caused by polymer solution of the same viscosity, increases. The average incremental oil recovery enhanced by polymer flooding is up to $4 \%$ when the residual resistance factor increases from 1.5 to 3 . The incremental recovery is as high as $18 \%$ when the residual resistance factor is 6 . In addition, it also proved that a low concentration of HAP 0312 solution can meet the requirement for residual resistance factor and high oil recovery is achieved in heavy oil reservoirs during polymer flooding due to increased residual resistance factor.

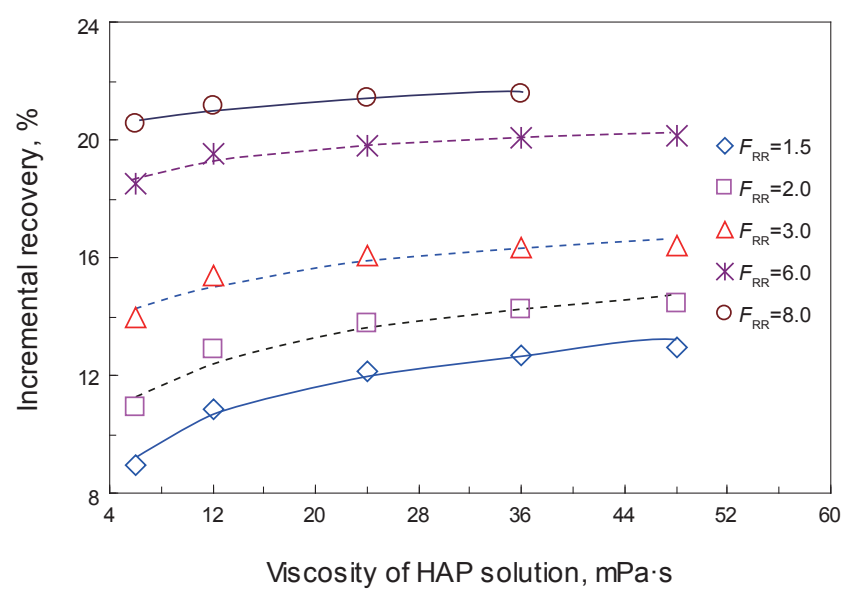

Fig. 5 The effect of residual resistance factor and viscosity on polymer flooding recovery

Meanwhile, one major impediment to the polymer flooding is the high cost of polymers required to increase solution viscosity. Effective mobility control can be achieved in heavy oil reservoirs by simultaneously increasing the residual resistance factor and viscosity of polymer solution, which results in high displacement efficiency. Hydrophobic groups in HAP associate together in the aqueous solution by intermolecular associations that increase the solution viscosity and thus produce a high resistance effect (residual resistance factor). If the solution viscosity and increased resistance effect meet the requirements simultaneously, the displacement effect of polymer flooding in heavy oil reservoirs can be improved. Better results from polymer flooding in heavy oil reservoirs can be obtained by increasing the residual resistance factor without greatly increasing the effective in-situ viscosity and it can effectively enlarge the application of polymer flooding in heavy oil reservoirs.

\section{Conclusions}

1) Higher mobility control of polymer solution is required by polymer flooding in heavy oil reservoirs than in conventional reservoirs. The demand for polymer flooding in heavy oil reservoirs can not be met solely by relying on the viscosity of the polymer solution.

2) It is feasible to effectively control the mobility of polymer solution by increasing the residual resistance factor as well as to decrease the demand for viscosity of polymer solution.

3 ) Increasing the residual resistance factor would significantly improve polymer flooding efficiency in heavy oil reservoirs.

\section{Acknowledgements}

This paper was supported by the National High Technology Research and Development Program of China (863 Program: 2006AA09Z315 and 2007AA090701-3)

\section{References}

Aktas F, Clemens T, Castanier L M, et al. Viscous oil displacement with aqueous associative polymers. Paper SPE 113264 presented at SPE/ DOE Symposium on Improved Oil Recovery, 20-23 April 2008, Tulsa, Oklahoma, USA

Chen J C, Shi M, Gao X M, et al. Effects on resistance factor and residual resistance factor for polymer solution flow through porous media. Journal of Daqing Petroleum Institute. 1992. 16(3): 31-36 (in Chinese)

Du Y H, Wu X C, Chen H, et al. Application of moveable gel displacement adjustment in conventional heavy oil reservoirs. Journal of Southwest Petroleum University. 2008. 30(3): 97-102 (in Chinese)

Eoff L, Dalrymple D, Reddy B R, et al. Development of a hydrophobically modified water-soluble polymer as a selective bullhead system for water-production problems. Paper SPE 80206 presented at International Symposium on Oilfield Chemistry, 5-7 February 2003, Houston, Texas, USA

Guo L L, Li Z Q, Li S R, et al. Optimization of oil-to-polymer viscosity ratios in the primary and secondary polymer flooding. Acta Petrolei Sinica. 2008. 29(5): 738-741 (in Chinese)

Han M, Xiang W T, Zhang J, et al. Application of EOR technology by means of polymer flooding in Bohai Oil Fields. Paper SPE 104432 presented at International Oil \& Gas Conference and Exhibition in China, 5-7 December 2006, Beijing, China

Jiang $\mathrm{M}$ and $\mathrm{Xu} \mathrm{Z}$ F. Study of polymer flooding of Liaohe Heavy Oil Reservoir. Journal of Hydrodynamics. 1999. 14(2): 240-246 (in Chinese)

Jiang Y L. Technical Condition Optimization of Polymer Flooding. Beijing: Petroleum Industry Press. 1993. 64-70 (in Chinese)

Levitt D B and Pope G A. Selection and screening of polymers for enhanced oil recovery. Paper SPE 113845 presented at SPE/DOE Symposium on Improved Oil Recovery, 20-23 April 2008, Tulsa, Oklahoma, USA

Li S Q, Li Y Q, Li J Y, et al. Research and Application of Polymer and Colloidal Dispersion Gel System Flooding in Daqing Xingnan Oilfield. Beijing: Petroleum Industry Press. 2006. 91-102 (in Chinese)

Liu Y Z. Polymer Flooding to Enhance Oil Recovery Technology. Beijing: Petroleum Industry Press. 2006. 59-61 (in Chinese)

Niu Y B, Ouyang J, Zhu Z Y, et al. Research on hydrophobically associating water-soluble polymer used for EOR. Paper SPE 65378 presented at SPE International Symposium on Oilfield Chemistry, 13-16 February 2001, Houston, Texas

Ren K, Wang J L, Lin M Q, et al. Rheological properties of hydrophobically associating polyacrylamide solution. Petroleum Science. 2006. 2(3): 68-74

Shen P P, Yuan S Y, Deng B Y, et al. Quantitative description of the effects of sweep efficiency and displacement efficiency during chemical flooding on a heterogeneous reservoir. Petroleum Science. 2004. 1(3): 41-48 
Song W C. Techniques and Methods of Oil Field Development in the Period of High Water Cut. Beijing: Geological Publishing House. 2003. $432-433$ (in Chinese)

Vasquez J, Eoff L and Dalrymple D. Laboratory evaluation of a relative permeability modifier for profile modification in injection wells. Paper SPE 121789 presented at Latin American and Caribbean Petroleum Engineering Conference, 31 May-3 June 2009, Cartagena de Indias, Colombia

Wang D M, Chen J C, Wu J Z, et al. Application of polymer flooding technology in Daqing Oilfield. Acta Petrolei Sinica. 2005. 26(1): 74 78 (in Chinese)

Wu Z X, Shi Z C, Hou X F, et al. Application of resistance coefficient to optimizing parameters in polymer flooding. Petroleum Geology and Recovery Efficiency. 2006. 13(1): $92-95$ (in Chinese)

$\mathrm{Xu}$ J F, Chen L S, Li C T, et al. Evaluation on adaptability of super high molecular polymer flooding of ordinary heavy oil. Oil Drilling \& Production Technology. 2007. 23(3): 63-67 (in Chinese)

Ye Z B, Jia T Z, Shi L T, et al. The mobility control capacity of hydrophobic associating polymer in high permeability porous media. Journal of Southwest Petroleum University. 2007. 29(5): 100-104

Ye Z B. The Principle of Enhanced Oil Recovery. Beijing: Petroleum
Industry Press. 2007. 25-36 (in Chinese)

Zhang X S, Sun F J, Feng G Z, et al. Research on influence factors of polymer flooding and its field testing in Bohai Heavy Oil Fields. China Offshore Oil and Gas. 2007. 19(1): 30-34 (in Chinese)

Zhou S W. The study and application of new mode of effective development of offshore heavy oil field. Journal of Southwest Petroleum University. 2007. 29(5): 1-4 (in Chinese)

Zhou W, Zhang J, Feng G, et al. Key technologies of polymer flooding in offshore oilfield of Bohai Bay. Paper SPE 115240 presented at SPE Asia Pacific Oil and Gas Conference and Exhibition, 20-22 October 2008, Perth, Australia

Zhou W, Zhang J, Han M, et al. Application of hydrophobically associating water-soluble polymer for polymer flooding in China offshore heavy oilfield. Paper SPE 11635 presented at International Petroleum Technology Conference, 4-6 December 2007, Dubai, U.A.E.

Zhou Y B, Lu J P, Li Y Q, et al. Evaluation of polymer flooding pilot in ordinary heavy oil reservoirs in Shengtuo Oilfield. Henan Petroleum. 2004. 18(2): 29-32 (in Chinese)

(Edited by Sun Yanhua) 